\title{
$=\mathrm{T} R A M A=$
}

\section{CAPACITISMO: ENTRE A DESIGNAÇÃO E A SIGNIFICAÇÃO DA PESSOA COM DEFICIÊNCIA}

\author{
ANDRESSA MARCHESAN (UFSM) ${ }^{1}$ \\ https://orcid.org/0000-0002-6467-8457 \\ REJANE FIEPKE CARPENEDO (UFSM) ${ }^{2}$ \\ https://orcid.org/0000-0001-7151-666X
}

\begin{abstract}
RESUMO: Nas discussões atuais que envolvem as questões referentes à pessoa com deficiência, uma nova designação tem ganhado espaço. Trata-se do capacitismo, expressão que designa o preconceito em relação às pessoas com deficiência, que surge a partir do fato de que no senso comum pressupõe-se que o sujeito com deficiência possui todas as suas capacidades limitadas ou reduzidas, constituindo-se em uma pessoa automaticamente "menos capaz". Assim, o presente artigo tem por objetivo compreender o funcionamento semântico das reescriturações da designação capacitismo. O aporte teórico-metodológico se dá a partir da teoria da enunciação, com foco na Semântica do Acontecimento, postulada por Guimarães (2018), que mobiliza a enunciação enquanto um acontecimento histórico-social, inscrito no espaço e no tempo. Nosso corpus se constitui a partir de três recortes de uma reportagem do jornal Estadão, em que diferentes entrevistados apresentam a sua perspectiva em relação à temática do capacitismo, a partir das suas próprias vivências. Com base no movimento analítico, observamos que a designação capacitismo se reescreve, majoritariamente, pelo modo de elipse e expansão, e o sentido por definição, especificação e desenvolvimento, apresentando um imaginário de que as pessoas com deficiência são automaticamente incapazes e que têm as suas habilidades restritas em todas as esferas da sua vida, o que costuma não ser verídico, como enunciado pelos próprios entrevistados. O capacitismo acolhe um conjunto de sentidos que revelam preconceitos e estereótipos socialmente construídos e historicamente difundidos, que hoje perpassam os discursos do senso comum.
\end{abstract}

PALAVRAS-CHAVE: Capacitismo. Deficiência. Semântica do Acontecimento.

ABSTRACT: In the current discussions involving issues related to people with disabilities, a new name has been gaining ground. It is about capacitism, an expression that designates prejudice towards people with disabilities, which arises from the fact that in common sense it is assumed that the subject with disabilities has all his or her limited or reduced capacities, constituting themselves in an automatically "less capable" person. Thus, this article aims to understand the semantic functioning of the rewriting of the designation capacitism. The theoretical-methodological contribution comes from the enunciation theory, focusing on the Semantics of the Event, postulated by Guimarães (2018), which mobilizes the enunciation as a historical-social event, inscribed in space and time. Our corpus consists of three clippings from a report by the newspaper Estadão, in which different interviewees present their perspective in relation to the theme of capacitism from their own experiences. Based on the analytical movement, we observe that the designation capacitism is rewritten, mostly, by the ellipse and expansion mode, and the meaning by definition, specification and development, presenting a imaginary that people with disabilities are automatically incapable and what have their skills are restricted in all spheres of their life, which is usually not true, as stated by the interviewees

\footnotetext{
${ }^{1}$ Doutoranda em Letras pelo Programa de Pós-Graduação em Letras da Universidade Federal de Santa Maria. Mestra em Letras - Estudos Linguísticos - pela Universidade Federal de Santa Maria. Bacharela em Letras Português e Literaturas pela Universidade Federal de Santa Maria. E-mail: andressa.marchesan92@gmail.com 2 Doutoranda em Letras pelo Programa de Pós-Graduação em Letras da Universidade Federal de Santa Maria. Bolsista CAPES. Mestra em Letras - Estudos Linguísticos - pela Universidade Federal de Santa Maria. Graduada em Jornalismo pela Universidade Federal de Santa Maria. E-mail: rejanefiepke@gmail.com
} 


\section{$=$ TRAMA $=$}

themselves. Capacitism embraces a set of meanings that reveal socially constructed and historically widespread prejudices and stereotypes, which today permeate the discourses of common sense.

KEYWORDS: Capacitism. Deficiency. Semantics of the Event.

\section{INTRODUÇÃO}

Cabe ressaltar de início que este tema do capacitismo interessa-nos por trazer à tona a questão da significação e do sentido. Neste artigo, propomos uma análise da designação capacitismo, no intuito de compreender os seus sentidos e o modo como estes se reescrevem. Para realizar tal estudo, selecionamos como objeto de análise a reportagem intitulada "Capacitismo: pessoas com deficiência explicam o que é e como evitá-lo", do jornal Estadão, de São Paulo, publicada no dia 18 de outubro de 2020.

Desenvolveremos essa reflexão a partir do dispositivo teórico e analítico da Semântica da Enunciação, conforme ela é trabalhada pelo linguista Eduardo Guimarães $(2018,2002)$. Tomando alguns dos conceitos trabalhados pelo autor, compreendemos o modo como a designação capacitismo é reescriturada e significada em nosso corpus. Nosso objetivo é verificar como o sentido dessa palavra está agenciado no acontecimento em que ocorre, ou seja, no enunciado da reportagem.

Ao dizermos que a designação capacitismo significa no texto, entendemos o texto como um acontecimento enunciativo. Em cada acontecimento, uma mesma palavra, expressão, pode ter diferentes sentidos. No funcionamento do texto, temos algo que é reescriturado, algo que é retomado, ou melhor, re-significado, re-dito.

\section{A DEFICIÊNCIA NA HISTÓRIA: UM OLHAR ENUNCIATIVO}

Ao longo da história, observamos uma movimentação de sentidos referente à pessoa com deficiência; dentre esses sentidos, estão os discursos de exclusão, de segregação, os discursos religiosos, médicos, científicos, assistencialistas, integracionistas, inclusivos. Amaral (1995) ressalta que esse movimento de sentidos não ocorreu de uma forma linear, pois eles podem ainda conviver entre si.

Iniciamos trazendo à reflexão o discurso de exclusão. Nesse sentido, Silva (1987) comenta que os recém-nascidos eram examinados por uma comissão oficial composta de anciãos e se parecessem feios, disformes e franzinos eram lançados a um abismo, para a morte. Além disso, esses anciãos consideravam ruim, para a criança e para a república, que ela vivesse, visto não ser forte, saudável e rijo o suficiente para enfrentar a vida.

Conforme Figueira (2008), entre os séculos XIX e XX, houve o início das instituições e das entidades assistenciais no Brasil. Dentre as instituições criadas, estão o Imperial Instituto dos Meninos Cegos, que, mais tarde, foi denominado Instituto Benjamin Constante, e o Imperial Instituto dos Surdos-Mudos, mais tarde, denominado Instituto Nacional de Educação de Surdos (INES), ambas na cidade do Rio de Janeiro e fundadas pelo Imperador D. Pedro II.

Essas instituições tinham como propósito acolher e auxiliar a pessoa com deficiência; mas podem ser compreendidas, na prática social, como um modo segregatório, pois, ao retirálas do convívio social e isolá-las em um espaço específico, se estava delimitando o que a pessoa com deficiência podia dizer, ouvir, compreender do mundo. No discurso de segregação, valoriza-se o corpo forte para a luta em guerras, aquele que não correspondesse a esse ideal, era segregado ou até eliminado (SCHEWINSKY, 2004).

Do discurso de segregação passamos ao discurso religioso e ao Cristianismo. Este ressalta que o homem é "imagem e semelhança de Deus"; sendo Deus perfeito, a perfeição é 


\section{$=$ TRAMA $=$}

uma condição de ser, ou seja, ao se predeterminar a perfeição como condição de homem, aquele diferente, imperfeito, que não se inscrevesse nesse ideal era posto à margem (MAZZOTTA, 2005). "O diferente do preferível é [...] o refutável, o detestável, aquele que se deve evitar" (MENDES; PICCOLO, 2013, p. 289).

Em alguns setores da Igreja Cristã, a deficiência foi vista como um castigo divino e como o resultado da "punição atribuída à irresponsabilidade de alguns membros de uma sociedade permissiva" (MARQUEZAN, 2007, p. 81). Em razão disso, foram realizadas "ações de aprisionamento, tortura, açoites e outros castigos severos" (ARANHA, 1995, p. 65). Como afirmam Fernandes, Schlesener e Mosquera (2011, p. 134), "indivíduos com deficiência [...] eram vistos como feiticeiros ou como bruxos. Eram seres diabólicos que deveriam ser castigados para poderem se purificar". Essas crenças se enraizaram no seio religioso de determinadas épocas e se opunham completamente aos ensinamentos de Cristo, que afirmavam ser à base de sua doutrina.

O avanço da medicina favoreceu uma leitura organicista da deficiência, ou seja, a visão da deficiência passou de um problema teológico e/ou moral para um problema médico, favorecendo, assim, uma visão científica (ARANHA, 1995). Essa visão científica e médica têm como base as classificações, as categorias para delimitar, definir deficiências. Há um "modo de observação - de descrição e de compreensão" (ORLANDI, 1990, p. 95) sobre a pessoa com deficiência, sobre os diferentes tipos de deficiência, ou seja, há um estudo sobre, um conhecimento mais aprofundado, que é constituído "de objetividade".

Dentre os assistidos pelos jesuítas, que se instalaram no País para catequizar os índios, estão as pessoas com deficiência, o que é inferido a partir dos atendimentos realizados, como "problemas oculares, [...] paralisias, [...] males dos ossos" (FIGUEIRA, 2008, p. 30).

É através do sentido científico e médico que tem início à prática da reabilitação, "no sentido de atender às necessidades da pessoa com deficiência como um todo" (PACHECO; ALVES, 2007, p. 244). Na Inglaterra, foi dado o primeiro passo significativo em direção à reabilitação da pessoa com deficiência, pois, com o término da Primeira Guerra Mundial, foi criada a Comissão Central da Grã-Bretanha, que tinha como objetivo auxiliar na recuperação de pessoas mutiladas e reintegrá-las na sociedade (PACHECO; ALVES, 2007).

A guerra ocasionou vários tipos de lesões, que, em alguns casos, resultaram na deficiência. $O$ crescente número de deficiências em decorrência da guerra trouxe à tona a reabilitação, que além do "restabelecimento das funções físicas remanescentes do sujeito, [buscou] favorecer a melhora na qualidade de vida deste, tendo em vista aspectos bio-psicosociais" (PACHECO; ALVES, 2007, p. 245). Em seguida, vem o discurso integracionista, na qual é a pessoa com deficiência que deve se adaptar à sociedade.

A integração está fundamentada na normalização, em "aproximar" as pessoas com deficiência da normalidade, ou seja, quem deve adaptar-se ao meio é o sujeito. A diferença entre a integração e a inclusão reside no fato de que, enquanto a primeira enfatiza o “'aprontamento' do sujeito para a vida na comunidade" (ARANHA, 2001, p. 20), a segunda investe no desenvolvimento do sujeito e na criação de condições que garantam o acesso e a participação da pessoa com deficiência na sociedade, através de suportes, seja físico, seja psicológico, seja outro ainda.

$\mathrm{Na}$ inclusão social, "indivíduo e sociedade mobilizam-se para mudanças" (MARCHESAN, 2017, p. 109), ambos devem agir em conjunto para a inclusão acontecer na prática social, pois há intervenções tanto no processo de desenvolvimento do sujeito quanto no processo de reajuste social (ARANHA, 2001). A inclusão social ressalta que a deficiência não está na pessoa, mas na sociedade, no meio em que vive. De fato, a inclusão requer um longo caminho a ser percorrido, tendo em vista a transformação na prática social de todos. 


\section{$=$ TRAMA $=$}

Para Aranha (2001, p. 19), inclusão social é um

processo de ajuste mútuo, onde cabe à pessoa com deficiência manifestar-se com relação a seus desejos e necessidades e à sociedade, a implementação dos ajustes e providências necessárias que a ela possibilitem o acesso e a convivência no espaço comum, não segregado.

A inclusão social acontece quando há o processo de ajuste tanto da pessoa com deficiência quanto da sociedade. A inclusão é um processo em aberto, é algo a ser construído conjuntamente e que ainda necessita de planejamento, experimentação porque seu aprimoramento é necessário para as gerações futuras. Essa movimentação de sentidos referente à deficiência pode ser resumida da seguinte maneira:

Por muito tempo, a deficiência esteve relacionada a castigos divinos, seres amaldiçoados, explicações sobrenaturais, que segregavam ou excluíam a pessoa com deficiência da sociedade. Aos poucos, altera-se a associação da deficiência de algo divino, para um desvio biológico e, deste, para um aspecto social (MARCHESAN, 2017, p. 109).

Em cada contexto, a humanidade vê a deficiência e a pessoa com deficiência de um modo peculiar, são diferentes olhares ao longo do tempo, sem ser necessariamente algo linear.

\section{ENUNCIAÇÃO: NO MOVER DOS SENTIDOS}

Para compreender a questão de pesquisa proposta a partir da perspectiva da Semântica Histórica da Enunciação, debruçamo-nos a pensar brevemente nas relações e vertentes teóricas de que se constitui a Semântica do Acontecimento.

Ao realizar um estudo enunciativo, percebemos que Guimarães (2005) elabora a sua proposta teórica a partir de Benveniste e Ducrot. Esses dois autores fundamentam a sua teoria no modelo estruturalista saussureano, divergindo na questão da enunciação e do sentido, que não foi desenvolvida por Saussure, e se aproximando à teoria de Guimarães.

A enunciação ocorre, para Benveniste (2006, p. 82), no momento em que o locutor faz a língua funcionar, pois "a relação do locutor com a língua determina os caracteres linguísticos da enunciação. Deve-se considerá-la como o fato do locutor, que toma a língua por instrumento, e nos caracteres linguísticos que marcam esta relação". É nesse contexto que se produzem os enunciados, em uma relação mútua entre a enunciação e o locutor, considerando que um não existe sem o outro.

Ducrot (2001), por sua vez, parte dos pressupostos de Benveniste, porém pensa a enunciação como um ato de linguagem que ocorre no momento em que se fala, em outras palavras, compreende a enunciação como acontecimento, que está situado em um espaço e tempo. Desse modo, é da presença do sujeito por meio do enunciado em um espaço e tempo determinados que resultará no sentido.

Assim, o enunciado passa a ser considerado como uma unidade discursiva, pois se pensa uma relação de historicidade no interior do conceito de enunciação, o que lhe agregará um caráter social. Com isso, o fator sócio-histórico refletirá suas marcas no interior do enunciado e este consiste na relação entre o sujeito e a palavra. Assim sendo, o sentido de um enunciado passa a ser compreendido como um conjunto de formações imaginárias, formado pelo sujeito, o seu interlocutor e o tema tratado na relação de diálogo.

As formações imaginárias são compreendidas como "o lugar que A e B se atribuem cada um a si e ao outro, a imagem que eles se fazem de seu próprio lugar e do lugar do outro" (PÊCHEUX, 1997, p. 82). O sujeito com deficiência tem uma imagem de si mesmo e do outro, 


\title{
$=$ TRAMA $=$
}

bem como tem uma imagem do lugar do outro e do seu lugar. Isso traz à tona uma sucessão de imagens que viabilizam as relações sociais.

Em sua pesquisa de mestrado, Fiepke (2019, p. 32) estuda os imaginários sobre a língua, ao aprofundar-se no conceito de imaginário, afirma que "percebemos que o imaginário não consiste em um reflexo fiel do real, e que também não é uma ilusão falsa da realidade. No entanto, é uma espécie de rede de significações por meio da qual constituímos o nosso mundo para nós como sociedade". Assim, compreendemos que o imaginário é uma construção a partir da percepção dos sujeitos sobre a realidade que os cerca, esses imaginários se constituem sobre todos os âmbitos da sociedade, inclusive sobre a pessoa com deficiência.

De acordo com Benveniste (1989), o movimento integrado de uma unidade linguística não permite passar do limite do enunciado. Guimarães (2002) não concorda, afirmando que há uma passagem do enunciado para o texto, para o acontecimento e que este não é segmental. É importante destacarmos alguns aspectos referentes aos estudos da Teoria da Enunciação, pois frequentemente aparecem descritos como conceitos de teorias da enunciação e linguística da enunciação. Nesse sentido, Flores e Teixeira explicam essa relação:

\begin{abstract}
Em suma, falamos em teorias da enunciação (no plural) e em linguística da enunciação (no singular) para salientar o fato de que se, por um lado, existe uma diversidade que permite considerarmos mais de uma teoria da enunciação, por outro, verificamos que há traços comuns a todas as perspectivas. Em outras palavras, acreditamos na unicidade referencial da expressão linguística da enunciação. No entanto, isso não deve levar a crer que procedemos a uma planificação das teorias com a finalidade de alcançar o objetivo de unificá-las em um campo de saber $(2005$, p. 8$)$.
\end{abstract}

Assim, compreendemos que as teorias da enunciação se constituem a partir do reconhecimento de que existem distintas teorias que a estudam. Já a linguística da enunciação se constitui por possuir traços comuns em todas as perspectivas enunciativas. Conforme Flores e Teixeira (2005), os estudos linguísticos no campo da enunciação são oriundos essencialmente da perspectiva benvenistiana, que pensa o discurso a partir do modelo de Saussure e reformula os conceitos no plano da língua, considerando a fala, ou seja, pensando a subjetividade. Posteriormente, fundamentado em um conceito estruturalista semelhante a Benveniste, mas com modo diferente de compreender a enunciação, surgem os estudos de Oswald Ducrot, também na França.

Após realizar esse breve percurso teórico, detemo-nos nos pressupostos de Guimarães, especialmente para compreender como se dá o funcionamento da expressão capacitismo enquanto uma designação. Para o autor:

\begin{abstract}
A designação é o que considero a significação de um nome enquanto sua relação com outros nomes e com o mundo recortado historicamente pelo nome. A designação não é algo abstrato, mas linguístico e histórico. Ou seja, é uma relação linguística (simbólica) remetida ao real, exposta ao real. Por isso um nome não é uma palavra que classifica objetos, incluindo-os em certos conjuntos (GUIMARÃES, 2013, p. 54).
\end{abstract}

Podemos pensar o capacitismo em sua relação com o mundo recortado historicamente e fazer isso implica considerar a historicidade no que tange à questão da deficiência, como refletido em nosso primeiro capítulo. Capacitismo se constitui como uma designação, pois designa atitudes preconceituosas em relação à pessoa com deficiência.

Além disso, torna-se relevante explicitarmos o que é acontecimento, conforme Guimarães. Para o autor, o acontecimento da enunciação "é diferença na sua própria ordem" (GUIMARÃES, 2002, p. 12) e essa diferença ocorre a partir da temporalização. Essa 


\title{
$=$ TRAMA $=$
}

temporalidade é constituída por um presente, por um futuro que "abre o lugar dos sentidos" (GUIMARÃES, 2002, p. 12) e por um passado que se refere à rememoração de enunciações outras. Sem o acontecimento não existe sentido, não existe enunciação.

O acontecimento está relacionado a certa ordem porque isso the garante uma significação. Como afirma Guimarães (2018, p. 39), o acontecimento "precisa levar este presente do texto em conta", ou seja, o acontecimento está relacionado ao texto em que está integrado. Então, os enunciados que aqui serão analisados estão vinculados ao texto que constitui nosso corpus; no caso em estudo, estão relacionados a uma reportagem sobre capacitismo.

\section{SENTIDOS DE CAPACITISMO}

Antes de adentrarmos em nossa análise, cabe destacar a definição de capacitismo presente no Glossário de termos relacionados à acessibilidade e deficiência ${ }^{3}$, da Câmara dos Deputados:

\begin{abstract}
Capacitismo: ato de discriminação, preconceito ou opressão contra pessoa com deficiência. É barreira atitudinal. Em geral, ocorre quando alguém considera uma pessoa incapaz, por conta de diferenças e impedimentos corporais. O capacitismo está focalizado nas supostas "capacidades das pessoas sem deficiência' como referência para mostrar as supostas 'limitações das pessoas com deficiência'. No capacitismo, a ênfase é colocada nas supostas 'pessoas capazes', as quais constituem a maioria da população e são supostamente consideradas 'normais'.
\end{abstract}

Podemos observar que o capacitismo é uma forma de preconceito, de discriminação contra a pessoa com deficiência, faz parte da sociedade e envolve as capacidades que uma pessoa possui ou não. No caso da pessoa com deficiência, o imaginário traz à tona que essas pessoas não são capazes simplesmente por terem uma deficiência.

Segundo Fiona Kumari Campbell, professora sênior na Escola de Educação e Serviço Social da Universidade de Dundee na Escócia, costuma-se traduzir a palavra capacitismo a partir da palavra inglesa ableism; seu sentido está relacionado com a discriminação devido à condição de deficiência. Esse conceito refere-se ao poder e à temática do corpo, através da ideia de um padrão corporal, do corpo perfeito; além disso, sugere um distanciamento da capacidade e da aptidão existente nos seres humanos ${ }^{4}$. Segundo Dias (2013, p. 2), "capacitismo é a concepção presente no social que lê as pessoas com deficiência como não iguais, menos aptas ou não capazes para gerir as próprias vidas".

Nosso corpus é constituído de recortes de entrevistas presentes na reportagem "Capacitismo: pessoas com deficiência explicam o que é e como evitá-lo", do jornal Estadão, de São Paulo, publicada no dia 18 de outubro de 2020. Nessa reportagem, diferentes sujeitos são entrevistados a respeito da temática do capacitismo, no intuito de compreender qual é o seu entendimento sobre a questão e quais foram as experiências pessoais vivenciadas que se relacionam com o assunto. A partir do texto veiculado, recortamos três sequências enunciativas em que os sujeitos designam o capacitismo e buscamos compreender como os sentidos da expressão se reescrevem no enunciado. Para tal, nos ancoramos nos pressupostos teórico-

\footnotetext{
${ }^{3}$ Disponível em: https://www2.camara.leg.br/a-camara/estruturaadm/gestao-na-camara-dosdeputados/responsabilidade-social-e-ambiental/acessibilidade/o-programa/glossario.html. Acesso em: 30 out. 2020.

4 Informações baseadas na reportagem "O que é capacitismo?", escrita pela jornalista Leandra Migotto Certeza, no dia 14 de novembro de 2019, na Revista d'AzMina. Disponível em: https://azmina.com.br/colunas/o-que-ecapacitismo/. Acesso em: 30 out. 2020.
} 


\title{
$=$ TRAMA $=$
}

metodológicos de Guimarães (2018), mais especificamente na reescrituração, que é definida como

\begin{abstract}
o modo de relação pelo qual a enunciação rediz o que já foi dito. Há reescrituração quando um elemento $Y$ de um texto (uma palavra, uma expressão, por exemplo) retoma um outro elemento $X$ do texto. Neste caso $Y$ reescritura $X$. Este modo de relação enunciativa leva a interpretar uma forma como diferente de si. O elemento que reescritura atribui (predica) sentido ao reescriturado. Uma característica fundamental da reescrituração é que ela não se caracteriza pelas relações segmentais, ou de contiguidade, própria dos modos de articulação (GUIMARÃES, 2018, p. 85).
\end{abstract}

Assim, uma vez mobilizadas as sequências enunciativas (SE), analisamos qual é o modo e qual é o sentido da reescrituração.

SE1: É algo opressor, preconceituoso, que categoriza determinadas formas de deficiência [...] parte do princípio de que pessoas com deficiência não são capazes de serem autônomas, terem uma vida.

Na SE1, o modo de reescrituração se dá por elipse, uma vez que fica facilmente subentendido que o enunciado se refere ao capacitismo, sendo este a temática da reportagem e a questão proposta para reflexão a cada entrevistado. A elipse consiste na omissão de um termo do enunciado que pode ser compreendido mesmo sem a sua presença.

Já o sentido da reescrituração se dá por definição e especificação. O enunciador define inicialmente o que é capacitismo e logo em seguida especifica o seu funcionamento. Capacitismo adquire o sentido de um elemento preconceituoso e opressor, que impõe discursivamente limitações aos sujeitos com deficiência, bem como questiona a capacidade de autonomia da pessoa com deficiência.

Observa-se que capacitismo é reescriturado por "opressor", "preconceituoso" e "que categoriza determinadas formas de deficiências". Essas três formas de definição são essenciais para compreendermos o sentido da designação capacitismo, pois delimitam seus sentidos, trazendo à tona sentidos negativos. Segundo o Dicionário Eletrônico Houaiss (2009, s.p.), opressor é "[...] aquele que oprime, que sujeita à opressão"; para entender o sentido de opressor torna-se necessário explicitarmos o sentido de opressão no mesmo dicionário: "[...] 4 constrangimento ou pressão moral; coação 5 humilhação, embaraço, vexame" (HOUAISS, 2009 , n. p.). Então, um dos sentidos de capacitismo está relacionado ao constrangimento, à humilhação da pessoa com deficiência devido a sua deficiência, ou seja, refere-se a uma atitude que desqualifica a pessoa com deficiência em razão de sua deficiência.

A segunda definição presente na SE1 é "preconceituoso", este está "baseado em ou que revela preconceito; [...] cheio de preconceitos; intolerante" (HOUAISS, 2009, n. p.). Como essa definição traz à tona preconceito, cabe ressaltar seu sentido:

\footnotetext{
qualquer opinião ou sentimento concebido sem exame crítico [...] ideia, opinião ou sentimento desfavorável formado sem conhecimento abalizado, ponderação ou razão [...] sentimento hostil, assumido em consequência da generalização apressada de uma experiência pessoal ou imposta pelo meio; intolerância (HOUAISS, 2009, n. p.).
}

Observamos a partir da definição de preconceito, que o capacitismo faz alusão a uma opinião desfavorável sobre a pessoa com deficiência, uma opinião prévia, muitas vezes, baseada no imaginário acerca da pessoa com deficiência, no qual esta é vista como alguém sem capacidade de ter autonomia e independência para gerir a própria vida. 


\section{$=$ TRAMA $=$}

A terceira definição presente na SE1 está vinculada a algo "que categoriza determinadas formas de deficiência"; assim, importa destacar o sentido de categorizar: "dispor em categorias; ordenar, classificar" (HOUAISS, 2009, n. p.). O capacitismo é concernente a classificar algumas formas de deficiências, principalmente as deficiências que mais afetam a capacidade de independência da pessoa, como as deficiências visual total, física, intelectual. Esses tipos de deficiência tendem a ser permeadas pelo imaginário da dependência, pela não capacidade de autonomia da pessoa com deficiência, não levando em conta que qualquer pessoa é capaz de ser autônoma e independente, basta inclui-la por meio de atitudes e de acessibilidades arquitetônicas.

SE2: O capacitismo é essa possibilidade que as pessoas têm de hierarquizar as vidas humanas, elegemos o que é normal, o que achamos que é. Mas isso é algo absolutamente arbitrário, uma construção social, que varia na época e sociedade [...] Tem a ver com a expectativa que se coloca sobre essas pessoas [com deficiência], que é baixa, a incapacidade de presumir competências, de pessoas com deficiência não serem vistas como sujeitos, que não podem decidir de si, não ter protagonismo.

A SE2 apresenta o modo de reescrituração por expansão, ao expandir a descrição sobre o que vem a ser a designação. O sentido ocorre por definição e desenvolvimento. Inicialmente, o enunciador define a expressão e posteriormente desenvolve o enunciado apresentando argumentos que visam justificar a sua definição. O movimento de reescrituração apresenta uma reflexão sobre um discurso socialmente construído acerca da pessoa com deficiência e que por se difundir no âmago do imaginário do senso comum e sustentar-se sobre preconceitos, sufoca as competências do sujeito com deficiência, a partir de ideias préconcebidas.

Na SE2, capacitismo é reescriturado por "hierarquizar as vidas humanas", "elegemos o que é normal, o que achamos que é", "a expectativa que se coloca sobre essas pessoas [com deficiência], que é baixa" e "não ter protagonismo". Esses modos de reescrituração trazem à baila outros sentidos para a mesma designação. Na primeira e na segunda definição, observamos um único sentido, pois tal designação hierarquiza vidas humanas ao delimitar, através do imaginário do senso comum, o que é normal e o que difere do "normal". A partir desse viés, podemos salientar o sentido de hierarquizar: "organizar de acordo com uma ordem hierárquica" (HOUAISS, 2009, n. p.). Assim, torna-se possível afirmar que a designação estudada tende a priorizar o normal, compreendido como alguém sem deficiência, em detrimento daquele que difere do considerado socialmente como normal, a pessoa com deficiência.

A terceira definição presente na SE2 é "a expectativa que se coloca sobre essas pessoas [com deficiência], que é baixa". Nessa definição, o sentido refere-se à expectativa, qualificando-a como baixa. Com o intuito de compreender esse sentido, explicitaremos o que é expectativa: "situação de quem espera a ocorrência de algo, ou sua probabilidade de ocorrência, em determinado momento" (HOUAISS, 2009, n. p.) e baixo: "que está abaixo de certo nível considerado o usual ou o ideal [...] que não tem capacidade para algo" (HOUAISS, 2009 , n. p.). Com base no capacitismo, é possível observar que se espera pouco, abaixo do usual, das pessoas com deficiência, como se elas não fossem capazes.

A quarta definição presente na SE2 é "não ter protagonismo". Essa definição está baseada na negação do protagonismo, em não ser protagonista. Para uma melhor compreensão, apontaremos o sentido de protagonista: "[...] indivíduo que tem papel de destaque num acontecimento" (HOUAISS, 2009, n. p.). Nessa definição, a pessoa com deficiência não tem um lugar de destaque na sociedade, ela fica à margem, assistindo outras 


\section{$=$ TRAMA $=$}

pessoas serem protagonistas, o que está presente no imaginário acerca da pessoa com deficiência.

SE3: (O capacitismo) É a ideia falaciosa de que existe uma capacidade plena. E quando falamos disso esquecemos que ela não existe, mas quem possui essa ideia falaciosa é quem está no poder. Ele é uma estrutura de dominação, como o racismo, machismo, que tenta desconectar desses valores construídos para explicar por que permanecemos na margem da sociedade.

$\mathrm{Na}$ SE3, o modo de reescrituração acontece por elipse e expansão. A elipse consiste na substituição da designação capacitismo pelo pronome ele, por "ideia falaciosa de que existe uma capacidade plena", bem como na supressão representada pela conjunção "que". o sentido se dá por definição e desenvolvimento.

No modo de reescrituração por expansão, a designação capacitismo é enunciada como sinônimo de estrutura de dominação, funcionando a partir da influência do poder que estaria no cerne da difusão de ideias que não se concretizam na prática, como o imaginário da existência das capacidades plenas e que, portanto, estes sujeitos estariam acima de qualquer limitação. Perpetuar a ideia da capacidade plena consiste em fomentar um discurso capacitista que exclui, categoriza, segrega os sujeitos de acordo com o imaginário que se concebe a respeito de suas habilidades.

Capacitismo é reescriturado por "ideia falaciosa de que existe uma capacidade plena" e "é uma estrutura de dominação" na SE3. Para entendermos a primeira definição devemos verificar o sentido de "falacioso", "capacidade" e "plena". "Falacioso" diz respeito a algo "que emprega falácia; enganoso" (HOUAISS, 2009, n. p.). "Capacidade" refere-se à "qualidade ou condição de capaz" (HOUAISS, 2009, n. p.). "Pleno" remete a algo "que está completo, inteiro" (HOUAISS, 2009, n. p.). A partir disso, podemos afirmar que, nessa definição, capacitismo remete a uma falsa condição de capacidade completa, ou seja, a pessoa com deficiência não teria a capacidade completa, plena, em virtude da sua deficiência.

Já a segunda definição presente na SE3 reescritura outro sentido para capacitismo "estrutura de dominação". Cabe ressaltar o que é "estrutura" e "dominação". Esta é a "[...] tendência de lutar por ascendência sobre os outros nas relações com estes mantidas, a qual se manifesta por meio de hierarquias bem estabelecidas". Aquela é "aquilo que dá sustentação a alguma coisa" (HOUAISS, 2009, n. p.). A designação em estudo é definida como algo que pertence a uma estrutura social que busca dominar as pessoas com deficiência, inserindo-as em um lugar à margem na sociedade.

Observamos que nas três SEs são explicitados sentidos negativos em relação à pessoa com deficiência, o que caracteriza a designação em estudo. Dentre os sentidos negativos destacam-se: não protagonista, não ter capacidade de autonomia e independência, falsa ideia de capacidade plena, baixa expectativa acerca das pessoas com deficiência. Em algum momento elas trazem a negação, por meio do advérbio "não", dos adjetivos "falso" e "baixo".

\section{CONSIDERAÇÕES FINAIS}

Pensar a questão do capacitismo implica em refletir acerca de toda a história da pessoa com deficiência, a partir de um recorte temporal e espacial, o que fizemos inicialmente. Capacitismo tornou-se uma designação, pois designa a discriminação, o preconceito contra a pessoa com deficiência, dá nome e atribui sentido a sentidos que já estavam postos. Assim, com esse movimento instaura outros sentidos. Além disso, é possível compreender como se constitui o imaginário que sustenta as ideias reproduzidas pelo discurso do capacitismo. 


\section{$=\mathrm{T} R A M A=$}

Enxergar a pessoa com deficiência com base em uma perspectiva pré-concebida, limitante por natureza, provém de uma constituição sócio-histórica de pensamentos que fundamentam uma série de preconceitos. Esses pensamentos resultam em ideias que passam a ser disseminadas pelas mais distintas esferas sociais e acabam por afetar todos os sujeitos com deficiência, porque pressupõe que esses sujeitos possuem limitações que Ihes incapacitam em todas as instâncias da vida, fazendo com que suas capacidades sejam suprimidas por um discurso totalizante e excludente.

Observamos que os sentidos de capacitismo se reescrevem, de modo que há sempre um sentido que permanece. Este se refere ao imaginário de que existem pessoas com capacidades plenas, de que as pessoas com deficiência são incapazes por natureza. Esse imaginário engessa um discurso generalizador e impede a possibilidade de exercer um olhar individual sobre o sujeito com deficiência, no sentido de ter a sensibilidade de observar que não é possivel construir generalizações sobre a questão.

\section{REFERÊNCIAS}

AMARAL, L. A. Conhecendo a deficiência: em companhia de Hércules. São Paulo: Robe Editorial, 1995. ARANHA, M. S. F. Integração social do deficiente: Análise conceitual e metodológica. Temas em Psicologia, Ribeirão Preto, v. 3, n. 2, p. 63-70, 1995. Disponível em:

<http://pepsic.bvsalud.org/scielo.php?script=sci_arttext\&pid=s1413389x1995000200008>. Acesso em: 10 abr. 2018.

ARANHA, M. S. F. Paradigmas da relação da sociedade com as pessoas com deficiência. Revista do

Ministério Público do Trabalho, v. 11, n. 21, 2001. Disponível em:

<http://www.adiron.com.br/arquivos/paradigmas.pdf>. Acesso em: 10 ago. 2018.

BENVENISTE, É. Problemas de Linguística Geral I. Campinas: Pontes, 1989.

BENVENISTE, É. Problemas de Linguística Geral II. 2. ed. Campinas: Pontes, 2006.

DIAS, A. Por uma genealogia do capacitismo: da eugenia estatal a narrativa capacitista social. In: I SIMPÓSIO INTERNACIONAL DE ESTUDOS SOBRE A DEFICIÊNCIA - SEDPCD/DIVERSITAS/USP LEGAL, 2013, São

Paulo. ANAIS...

DUCROT, O. El Decir y Lo Dicho. Buenos Aires: Edicial S.A., 2001.

FERNANDES, L. B., SCHLESENER, A., MOSQUERA, C. Breve histórico da deficiência e seus paradigmas.

Revista do Núcleo de Estudos e Pesquisas Interdisciplinares em Musicoterapia, Curitiba, v.2, p.132-144,

2011.

FIEPKE, R. B. A reescrituração e os sentidos de língua na perspectiva do senso comum: ideologia e imaginário. Dissertação (Mestrado em Letras) — Universidade Federal de Santa Maria, Santa Maria, 2019. FIGUEIRA, E. Caminhando em Silêncio: Uma introdução à trajetória das pessoas com deficiência na história do Brasil. São Paulo: Giz Editora, 2008.

FLORES, V.; TEIXEIRA, M. Introdução à Linguística da Enunciação. São Paulo: Contexto, 2005.

GUIMARÃES, E. Semântica do Acontecimento: um estudo enunciativo da designação. Campinas, SP: Pontes, 2002.

GUIMARÃES, E. A língua portuguesa no Brasil. Ciência e Cultura, São Paulo, v. 57, n. 2, Abr./Jun. 2005. GUIMARÃES, E. Semântica: Enunciação e Sentido. Campinas, SP: Pontes Editora, 2018.

GUIMARÃES, E. Designação e Espaço de Enunciação: um encontro político no cotidiano. LETRAS, Santa Maria, UFSM, n. 26, p. 53-62, 2013.

HOUAISS, A.; VILLAR, M. S. Dicionário Eletrônico Houaiss da Língua Portuguesa. Elaborado pelo Instituto Antônio Houaiss de Lexicografia e Banco de Dados da Língua Portuguesa. Rio de Janeiro: Objetiva, 2009. MARCHESAN, A. Discurso sobre a deficiência e algumas possibilidades de sentidos. IN: ARENDT, J. C. [et al.] (Org.). Anais do $5^{\circ}$ Encontro da Rede Sul Letras. Caxias do Sul, RS: UCS; Porto Alegre: UNIRITTER, v. 1 , p. 107-116, 2017

MARQUEZAN, R. O discurso sobre o sujeito deficiente produzido pela legislação brasileira. 2007. 175 f. Tese

(Doutorado em Educação) - Universidade federal do Rio Grande do Sul, Porto Alegre, RS, 2007.

MAZZOTTA, M. J.S. Educação especial no Brasil: História e políticas públicas. 5. ed. São Paulo: Cortez Editora, 2005

MENDES, E. G.; PICCOLO, G. M. Sobre formas e conteúdos: a deficiência como produção histórica.

Perspectiva, Florianópolis, v. 31, n. 1, p. 283-315, jan./abr. 2013.

PACHECO, K. M. B.; ALVES, V. L. R. A história da deficiência, da marginalização à inclusão social: uma mudança de paradigma. Acta Fisiátrica, São Paulo, v. 14, n. 4, p. 242- 248, 2007.

PÊCHEUX, M. Análise Automática do Discurso (AAD-69). IN: GADEt, f.; HAK, t. (org.). Por uma análise automática do discurso: uma introdução à obra de Michel Pêcheux. Trad. Bethânia Mariani [et al.]. Campinas, SP: Editora da UNICAMP, 1997, p. 61-151. 
SCHEWINSKY, S. R. A barbárie do preconceito contra o deficiente: todos somos vítimas. Acta Fisiátrica, São Paulo, v. 11, n. 1, p. 7-11, abr. 2004.

Recebido em 31-10-2020 Revisões requeridas em 02-01-2021 Aceito em 11-01-2021 